\title{
Measurement and Analysis of Settlement Induced by Rectangular Pipe Jacking in Silt Stratum
}

\author{
Jun Tang $\mathbb{D}^{1,2}$ Shengcai Li, ${ }^{1}$ and Yongfu $\mathrm{Zhu}^{3}$ \\ ${ }^{1}$ School of Civil Engineering, Huaqiao University, Xiamen 361021, China \\ ${ }^{2}$ Xiamen Xijiao Hard Science Industrial Technology Research Institute Co.,Ltd., Xiamen 361008, China \\ ${ }^{3}$ Minnan University of Science and Technology, \\ Fujian Engineering Research Center for Construction and Management of Green Buildings, Quanzhou 362700, China \\ Correspondence should be addressed to Jun Tang; tangjun1123@stu.hqu.edu.cn
}

Received 4 August 2021; Revised 27 October 2021; Accepted 2 November 2021; Published 15 November 2021

Academic Editor: Yunzhong Jia

Copyright (c) 2021 Jun Tang et al. This is an open access article distributed under the Creative Commons Attribution License, which permits unrestricted use, distribution, and reproduction in any medium, provided the original work is properly cited.

\begin{abstract}
The large-scale rectangular pipe jacking technology has attracted more and more attention in the construction of urban underground pipe galleries, especially the problem of prediction and control of the surface settlement. Taking the pipe gallery project of Chengbei Road in Suzhou as an example, the settlement values of three groups of monitoring sections under the conditions of natural settlement and synchronous grouting are monitored, and the measured settlement values are compared with Peck formula and random medium theory. The results show that the Peck formula is more accurate in predicting the natural settlement within 1.5 times the pipe jacking width, while the stochastic medium theory is more accurate in predicting the settlement beyond the width. By comparing the field test and theory, the suggestions on the prediction of ground settlement of rectangular pipe jacking of large scale are put forward. The results of this study provide a basis for subsequent related research work and engineering applications.
\end{abstract}

\section{Introduction}

With the acceleration of urbanization, the expansion of underground space has gradually become a hot issue in the comprehensive utilization of urban space. Underground pipe jacking technology is one of the important ways to build a comprehensive pipe gallery in addition to the underground excavation technology. Pipe jacking construction will have a certain impact on the surface; in particular, large section pipe jacking construction in complex stratum will cause greater disturbance to the soil within the affected area [1-6].

In order to study the ground motion, many theoretical analyses have been carried out [7]. Previous studies have shown that the surface deformation is affected by the following factors: (i) ground loss, (ii) the pressure on the excavation surface, (iii) lateral friction on the hoist, (iv) grouting process [8], and (v) mechanical vibration [9], etc.

The research methods of surface deformation caused by pipe jacking mainly include experience method, theoretical analysis, numerical simulation, and actual field measurement analysis.

1.1. Empirical Method. Peck [10] obtained the conclusion that the land subsidence trough is typically distributed based on the analysis of the number of engineering measured data. The Peck formula for estimating the lateral ground settlement trough is proposed under the assumption that the soil is incompressible. After that, many scholars have put forward different methods for the values of width coefficient and soil loss in the Peck formula.

O'Reilly and New [11] treated drilling soil and granular soil differently and put forward different formulas for calculating width coefficients. Loganathan and Poulos [12] thought that the width coefficient is related to the tunnel depth and tunnel radius and so proposed new formula. Attewell and Farmer [13] used the cumulative probability curve formula to calculate the longitudinal ground subsidence of the ground directly above the 
tunnel axis. Based on the formula of O'Reilly and the empirical coefficient of Shanghai Metro, the soil loss is calculated.

1.2. Theoretical Analysis. There are two common theoretical analysis methods for the calculation of soil stress and displacement caused by underground engineering construction such as pipe jacking and tunnel construction: the classical theoretical analysis and the random theory analysis.

The classical theoretical analysis method is to use the solution of the concentrated force in the infinite and semiinfinite space in elastic mechanics and calculate the effect of construction on the surrounding soil stress and displacement by using the integral principle in the mathematical method [14]. The theory of random medium was proposed by Litwiniszyn [15] when studying the law of ground subsidence and movement caused by underground mining.

For the surface deformation caused by pipe jacking, researchers tend to choose the shield construction method for comparison. Sagaseta [16] assumes that the ground motion is uniform and the consolidation condition is undrained. Then, the three-dimensional deformation calculation is used to analyze the surface loss. Verruijt and Booker [17] divided the tunnel deformation into the same radial displacement and the self-elliptic deformation of the soil and obtained the calculation formulas of the vertical displacement and horizontal displacement of the soil through mathematics. Scholars [18] analyzed the ground settlement caused by shield excavation and proposed a method to estimate the ground settlement by using a cumulative probability curve. Ren et al. [19] proposed a theory of ground settlement caused by circular pipe jacking and compared it with the engineering case. Cheng et al. [20] studied pipe jacking engineering in Taiwan and analyzed the variation law of pipe jacking force when crossing different strata.

1.3. Numerical Simulation. The numerical simulation method is widely used to simulate the influence of pipe jacking construction on ground deformation [21]. Zhang et al. [22] conducted a 3D numerical simulation to investigate the responses of pipe jacking construction on the roadway. Based on the comparison between simulation results and field measurement, Zhang et al. proposed the technological methods to reduce the uplift and ground settlement of the tunnel.

Shimada et al. [23] found that mud properties play an important role in the jacking process, and appropriate mud pressure is the key to the stability of surrounding soil $[24,25]$. Bing et al. [26] did a 3D simulation and found that the transverse deformation range caused by pipe jacking is $-3.6 \mathrm{~d} \sim 3.6 \mathrm{~d}$, and the influence range of longitudinal surface deformation is-2.14 d 2.14d. According to a rectangular subway shield, Tang et al. [27] analyzed the deformation of the ground by ABAQUS three-dimensional finite element simulation software. The spatial and temporal distribution laws of the deformation of the settlement of the ground surface are summarized.
1.4. Method of Measurement and Analysis. Zhou et al. [28] simulated the influence of grouting on jacking force and surface settlement in silt areas and concluded that reasonable control of slurry parameters can effectively reduce friction and control surface settlement. Yang et al. [29] also obtained that if the mud performance can be improved, the jacking force in pipe jacking construction can be reduced and the jacking force can be predicted accurately. Sun et al. [30] adopted the field monitoring method to analyze the key parameters in the pipe jacking construction of double line underground pedestrian passage and presented geoenvironmental impacts of the rectangular pipe jacking technology. Zhang et al. [31] summarized four calculation methods of jacking force in the process of pipe jacking construction of Gongbei tunnel and compared with a field test. Li et al. [32] analyzed the possible causes of pipe cracking by way of detailed field investigation and on-site pipe strain monitoring. Stuedlein and Meskele [33] measured the ground deformation induced by mechanical vibration and compared the results with the vibration standard. The results show that the influence degree of mechanical vibration decreases rapidly with the increase of radial distance $[34,35]$.

Based on the theoretical analysis of Peck and random medium, the settlement law caused by rectangular pipe jacking in the large fault flour sand formation will be analyzed based on the field data.

\section{Project Background and Monitoring Methods}

2.1. Project Background. The total length of the comprehensive Underground Pipe Gallery project in Suzhou City is over 30 kilometers. And this project needs to traverse multiple urban inland rivers, main buildings, roads, and various municipal pipe networks. This paper takes the pipe gallery crossing the river section in Chengbei Road as the objective of research and analysis.

According to the site investigation, the comprehensive pipe gallery under the river is about 39 meters wide, and there is a simple building with four floors within 10 meters to the south end. The terminal position is under an overpass, and various underground pipelines such as water supply, rainwater, telecommunications, and optical fiber are passed down along the line. It is confirmed by drilling that the stratum layer crossed by the jacking pipe is silty sand mixed with silt and silt sand layer, and there is silt on the top of the pipe jacking partly underneath the river channel where the groundwater is abundant. In order to control ground settlement and ensure the safety of the surface and structure of the pipe jacking section, it is suggested to apply an Earth pressure balanced rectangular pipe jacking machine to carry out tunnel construction, and the performance parameters of the equipment are shown in Table 1.

The comprehensive pipe gallery adopts a section size of $5.5 \mathrm{~m} \times 9.1 \mathrm{~m}$, a wall thickness of $650 \mathrm{~mm}$, a pipe joint concrete strength of $\mathrm{C} 50$, and all the pipe jacking structures adopt prefabricated rectangular reinforced concrete pipe joints. 
TABLE 1: Technical parameters of the rectangular pipe jacking machine.

\begin{tabular}{lcc}
\hline Serial number & Content & Parameters \\
\hline 1 & Strata & Clay, sandy soil, and silty clay \\
2 & Shape & $5520 \mathrm{~mm} \times 9120 \mathrm{~mm}$ \\
3 & Form of the cutter head & Whole section cutting \\
4 & Deviation adjustment angle & Horizontal: $\pm 1.3^{\circ}$, vertical: $\pm 2.3^{\circ}$ \\
5 & Cutter head speed & $0 \sim 1.58 \mathrm{rpm}$ \\
6 & Screw speed & $0 \sim 6 \mathrm{rpm}$ \\
7 & Excavated volume & $60 \mathrm{~m}^{3} / \mathrm{h}$ \\
\hline
\end{tabular}

A typical section of the comprehensive pipe gallery is shown in Figure 1.

The drilling positions closest to the riverbed and riverbank are $\mathrm{J07}$ and J08, which are shown in Figure 2. According to the drilling data, the main types of crossing soil layer are miscellaneous fill, clay, silty clay, silt, etc., and the physical parameters of the soil layer are shown in Table 2.

2.2. Monitoring Methods. The comprehensive pipe gallery project from Jinzheng Street (Chengbei Road) to Jiangyu Road starts from east to west, and the jacking distance is $240.0 \mathrm{~m}$. Due to the large excavation section of rectangular pipe jacking, the influence on the ground deformation is particularly large. Therefore, three monitoring sections (CJ1 section, CJ2 section, and CJ3 section) are set up according to the geological conditions combined with the distribution of surface structures. Among these three monitoring sections, CJ1 is located on the current road, 69.4 meters away from the launching shaft; CJ2 is located between buildings, 111.4 meters away from the launching shaft; CJ3 is located along the river, 182.9 meters away from the launching shaft. The specific details are displayed in Figure 3.

The settlement observation points of each section are symmetrically arranged with the pipe jacking axis as the center. The distance between the inner measuring points within the width range of the jacking pipe is 1 meter, and outside the width range, the measuring points are arranged every 2 meters. There are 23 monitoring points on the CJ1 and CJ3 sections, respectively. Since the CJ2 section is located between the building groups, there are 3 fewer monitoring points on both sides of the jacking pipe axis. Taking CJ3 as an example, the distribution of the monitoring points is shown in Figure 3. The number of each monitoring point is numbered from the launching shaft section. The monitoring point number is composed of the monitoring section and the distance from the axis. The distance of the measuring point on the north side of the axis is positive, and vice versa.

The monitoring instruments and frequency are shown in Table 3.

The contents of monitoring and analysis are as follows:

(1) Analysis of the law of surface transverse settlement: The settlement of several monitoring sections (before, during, and after the cutter head passes through the monitoring sections) is monitored, and the development law of the width and shape of the rectangular pipe jacking is analyzed.
(2) Analysis of surface longitudinal settlement.

In this paper, the ground settlements along the pipe jacking axis are monitored, and the development law of the maximum uplift and settlement of the settlement in different jacking processes is analyzed.

\section{Monitoring Results}

3.1. Analysis of Daily Surface Settlement. In order to study the lateral settlement law on both sides of the axis in the pipe jacking process, the CJ1 section surrounded by more buildings is selected as the analysis object. The monitoring points are selected every $4 \mathrm{~m}$ from the outermost side with the purpose of simplifying the data to be processed. Therefore, the data of CJ-17, CJ1-13, CJ1-9, CJ1-4, CJ1-0, $\mathrm{CJ} 1+4, \mathrm{CJ} 1+9, \mathrm{CJ} 1+13$, and CJ1 +17 are selected, and the two groups of data with the same off-axis distance are compared.

3.1.1. Comparative Analysis of CJ1-17 and CJ1+17. The daily settlement and rate of change (CJ1-17 and CJ1 + 17) are shown in Figures 4 and 5, respectively. The maximum uplift of CJ1-17 occurred on October 30 and November 9, with a value of $5 \mathrm{~mm}$, and the maximum settlement occurred on November 7, with a value of $8 \mathrm{~mm}$. The maximum positive change of CJ1-17 settlement occurred on November 8 with a change rate of 9.13 , and the maximum negative change occurred on November 7 with a change rate of -12.07 .

The maximum uplift of CJ1 17 occurred on November 24 , with a value of $4 \mathrm{~mm}$, and the maximum settlement occurred on November 7, with a value of $6 \mathrm{~mm}$. The maximum positive change of $\mathrm{CJ} 1+17$ settlement occurred on November 8 with a change rate of 9.13 , and the maximum negative change occurred on November 7 with a change rate of -7.04 .

According to the linear fitting results, the changing trend of the two points is roughly the same. The ground deformation caused by pipe jacking at the beginning is the settlement and gradually tends to abscissa with the progress of jacking. The daily deformation will fluctuate between uplift and settlement. The maximum daily settlement of the two monitoring points is on November 7, but the maximum daily uplift is not on the same day. The results show that the daily deformation changes alternately and the maximum daily settlement change rate of the two points occurred on November 8 (positive) and November 7 (negative). In general, the change of CJ1-17 is greater than CJ1 17 . 


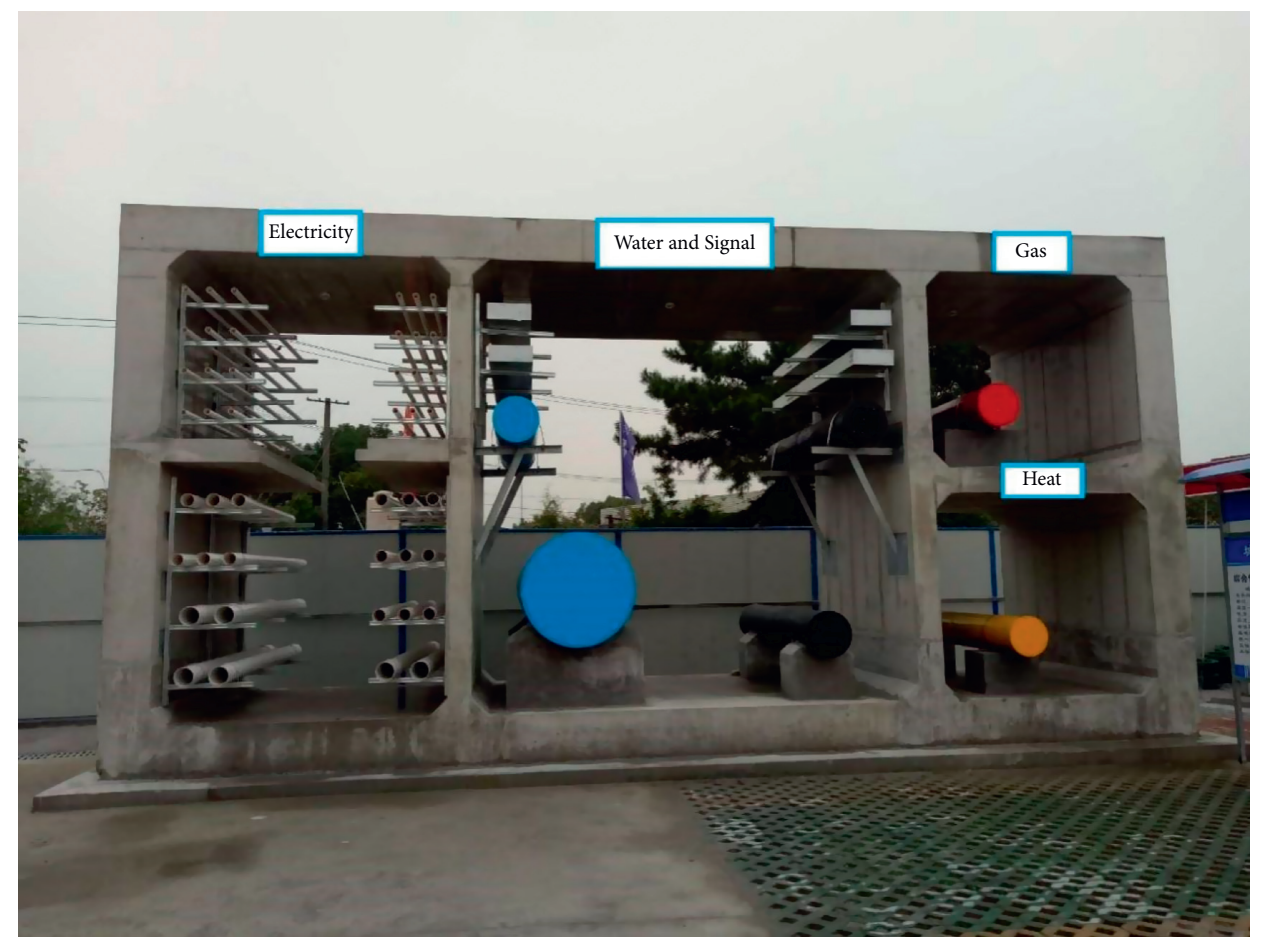

Figure 1: Typical section of comprehensive pipe gallery.

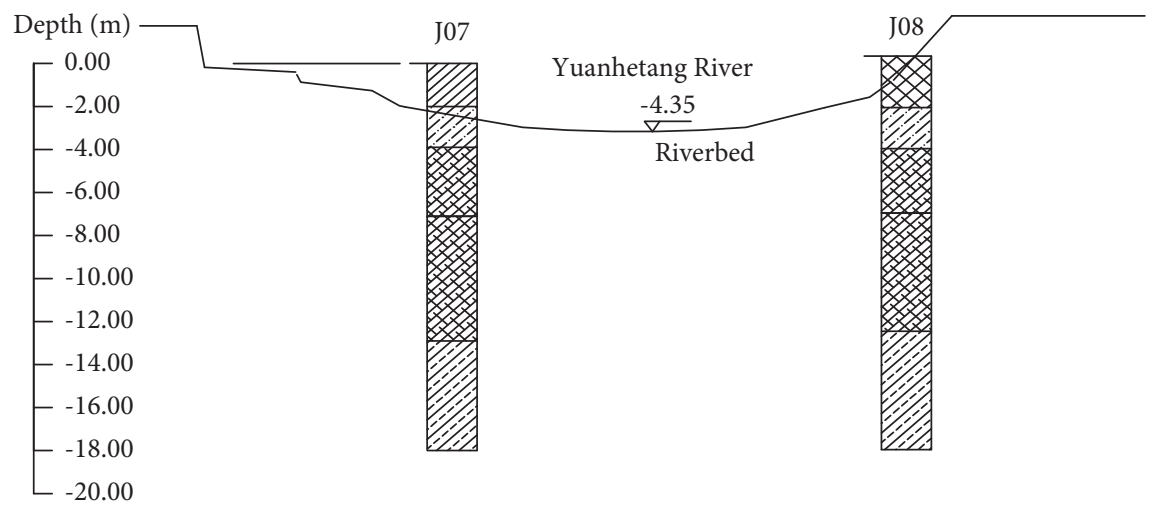

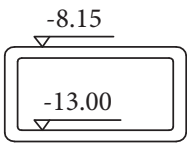

Pipe Jacking

$\begin{array}{ll}\text { Clay } & \text { Silt \& Soil } \\ \text { Silt } & \text { Silty Sand } \\ \text { Sill Clay \& Silt } & \text { Silty Clay }\end{array}$

FIgURE 2: Soil layer information and pipe jacking spatial location profile.

3.1.2. Comparative Analysis of CJ1-13 and CJ1+13. The daily settlement of CJ1-13 and CJ1 +13 is shown in Figure 6. The maximum uplift of CJ1-13 occurred on October 30, with a value of $6 \mathrm{~mm}$, and the maximum settlement occurred on November 7, with a value of $9 \mathrm{~mm}$. The maximum positive change of CJ1-13 settlement occurred on November 8 with a change rate of 8.11 , and the maximum negative change occurred on November 7 with a change rate of -13.07 .

The rate of change of daily settlement of CJ1-13 and $\mathrm{CJ} 1+13$ is shown in Figure 7. The maximum uplift of CJ1 13 occurred on November 24, with a value of $5 \mathrm{~mm}$, and the maximum settlement occurred on November 7 , with a value of $6 \mathrm{~mm}$. The settlement of CJ1 13 had the largest positive change on November 8 , with a change rate of 9.13 , and the largest negative change on November 7, with a change rate of -9.05 ;

According to the fitting results, the changing trend of the two sections is not completely coincident. The influence of pipe jacking on the surface deformation of CJ1-13 and CJ1 $1+13$ is settlement and uplift, respectively. The maximum daily settlement change rates of the two sections occurred on November 8 (positive) and November 7 (negative). The maximum daily settlement occurred on November 7 , but the maximum daily uplift is not on the same day. The results show that the change of CJ1-13 is slightly greater than CJ1 13 . 
TABLE 2: Physical mechanics parameters of soil layers.

\begin{tabular}{lccccccc}
\hline Name & Height & $\begin{array}{c}\text { Thickness } \\
h(\mathrm{~m})\end{array}$ & $\begin{array}{c}\text { Moisture rate } \\
\omega_{0}(\%)\end{array}$ & $\begin{array}{c}\text { Natural density } \\
\rho\left(\mathrm{g} / \mathrm{cm}^{3}\right)\end{array}$ & $\begin{array}{c}\text { Void ratio } \\
e---\end{array}$ & $\begin{array}{c}\text { Cohesion } \\
C(\mathrm{kPa})\end{array}$ & $\begin{array}{c}\text { Internal friction angle } \\
\varphi\left({ }^{\circ}\right)\end{array}$ \\
\hline Plain fill & 3.5 & 3.66 & 30.4 & 1.92 & 0.865 & 27.9 & 16.8 \\
Clay & -0.16 & 2 & 26.2 & 1.99 & 0.737 & 41.4 & 15.7 \\
Silty clay \& silt & -2.16 & 1.3 & 30.0 & 1.92 & 0.841 & 16.8 & 22.7 \\
Silt \& soil & -3.46 & 4.4 & 30.2 & 1.91 & 0.836 & 4.6 & 31.4 \\
Silt & -7.86 & 4 & 28.9 & 1.94 & 0.789 & 3.8 & 33.4 \\
Fine silty clay & -11.86 & 5.7 & 29.9 & 1.93 & 0.840 & 25.7 & 17.7 \\
\hline
\end{tabular}

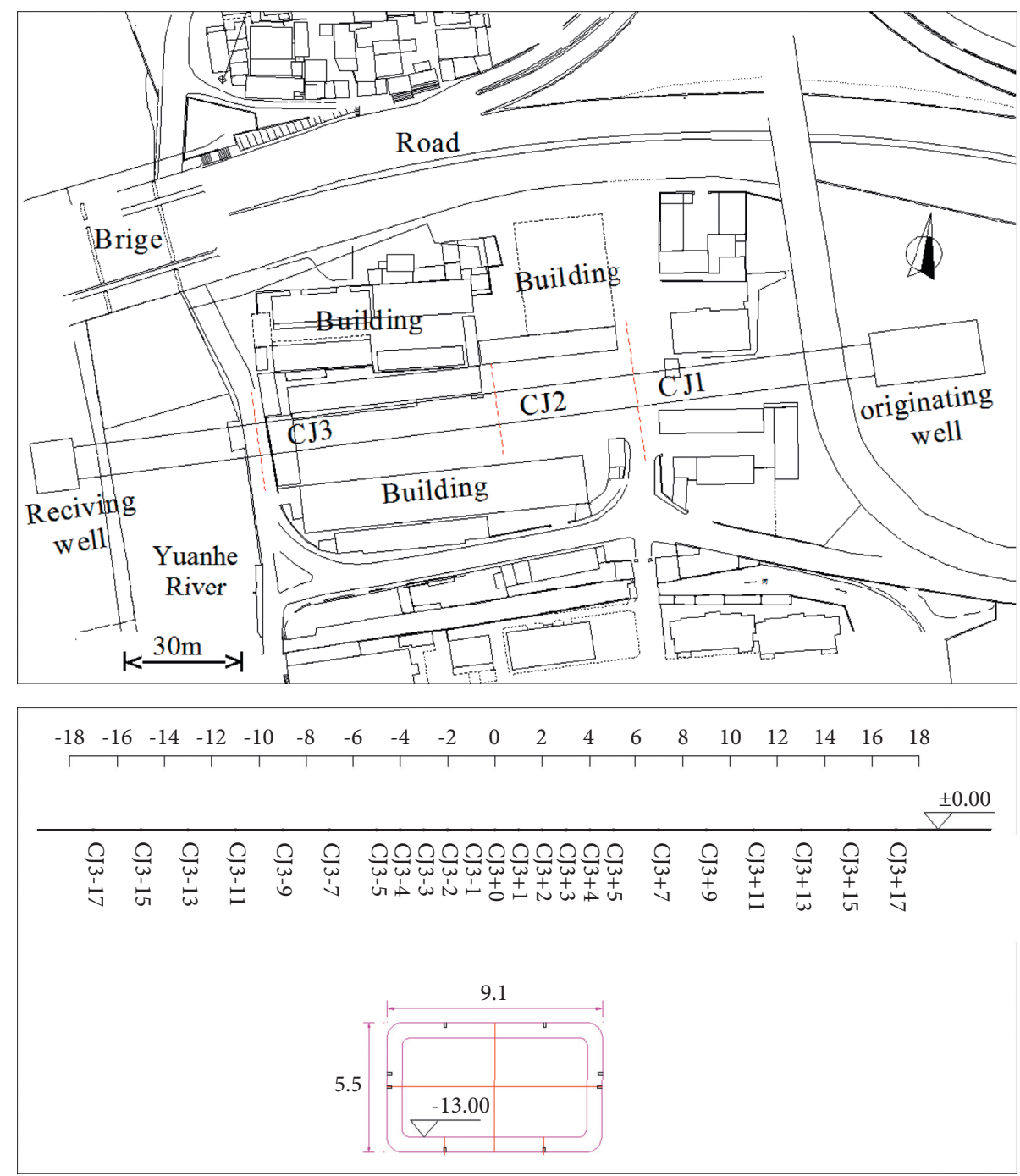

FIgURE 3: CJ3 plane layout of settlement monitoring points.

3.1.3. Comparative Analysis of CJ1-9 and CJ1 + 9. The daily settlement of CJ1-9 and CJ1+9 is shown in Figure 8. The maximum uplift of CJ1-9 occurred on September 25 with a value of $6 \mathrm{~mm}$, and the maximum settlement occurred on November 7 with a value of $9 \mathrm{~mm}$. The maximum positive change of CJ1-9 occurred on November 8, with a change rate of 13.18, and the maximum negative change was on November 7 , with a change rate of -13.07 .
The rate of change of daily settlement of CJ1-9 and CJ1 +9 is shown in Figure 9. The maximum uplift of CJ1 $1+9$ occurred on November 8 and November 24, with a value of $5 \mathrm{~mm}$, and the maximum settlement occurred on November 7 , with a value of $8 \mathrm{~mm}$. The largest positive change of CJ1 $1+9$ settlement occurred on November 8 , with a change rate of 13.18, and the largest negative change of CJ1+9 occurred on November 7 , with a change rate of -11.06 . 
TABLE 3: Surface settlement monitoring.

\begin{tabular}{|c|c|c|c|}
\hline Items & Instruments & $\begin{array}{c}\text { Number of Measured } \\
\text { point }\end{array}$ & Frequency \\
\hline Settlement & Optical level & 63 & $\begin{array}{l}\text { The distance between the pipe jacking head and the monitoring section is } 20 \mathrm{~m}, 1 \\
\text { times/d. } \\
\text { The cutter head is } 15 \mathrm{~m} \text { away from the monitoring section, } 1 \sim 2 \text { times/d. } \\
\text { After the cutter head passes through the monitoring section, it is continuously } \\
\text { monitored until the trend is stable, } 1 \text { times/d. }\end{array}$ \\
\hline
\end{tabular}

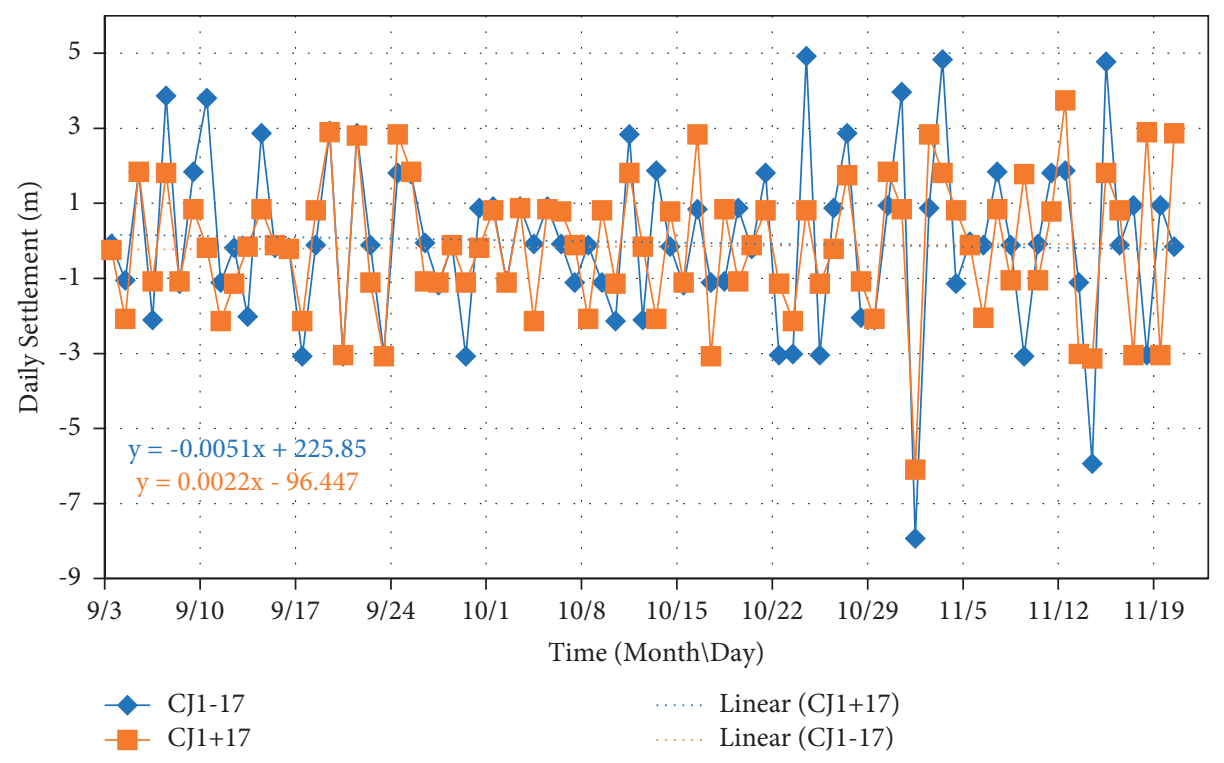

Figure 4: Daily settlement of CJ1-17 and CJ1 + 17 .

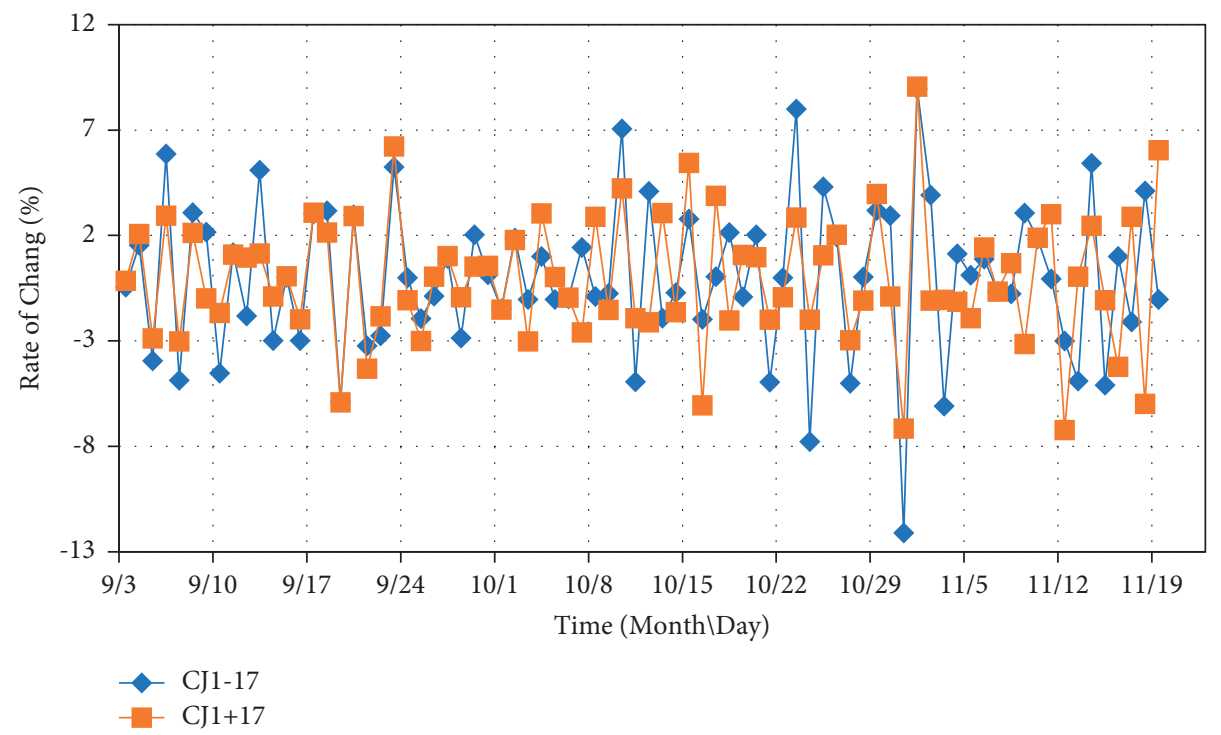

Figure 5: Rate of change of daily settlement (CJ1-17 and CJ1 + 17).

The maximum daily settlement of both sections occurred on November 7, but the maximum daily uplift do not occur on the same day. The maximum change rates of the two observation points occurred on November 8 (positive) and November 7 (negative).
3.1.4. Comparative Analysis of CJ1-4 and CJ1 + 4. The daily settlement and rate of change (CJ1-4 and CJ1 + 4) are shown in Figures 10 and 11, respectively. The maximum uplift of CJ1-4 occurred on November 8, with an amount of $8 \mathrm{~mm}$, and the maximum settlement occurred on November 7 , with 


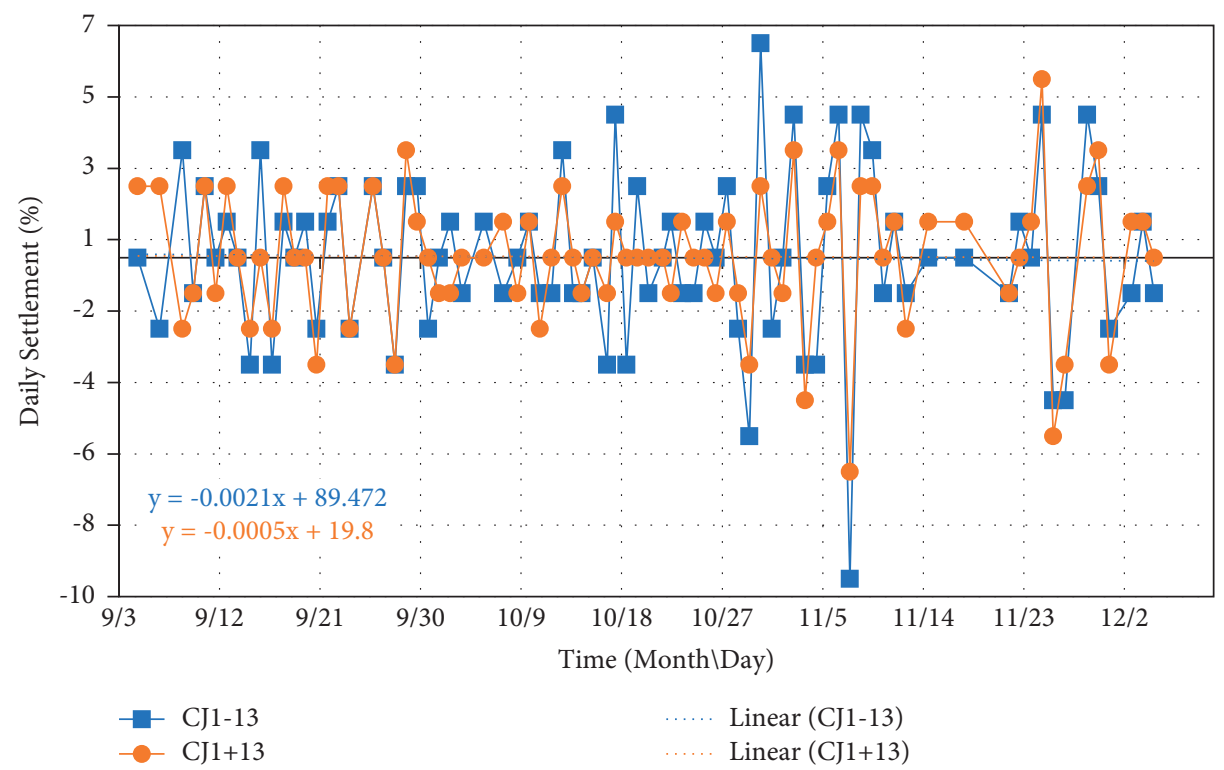

FIgURE 6: Daily settlement of CJ1-13 and CJ1 13 .

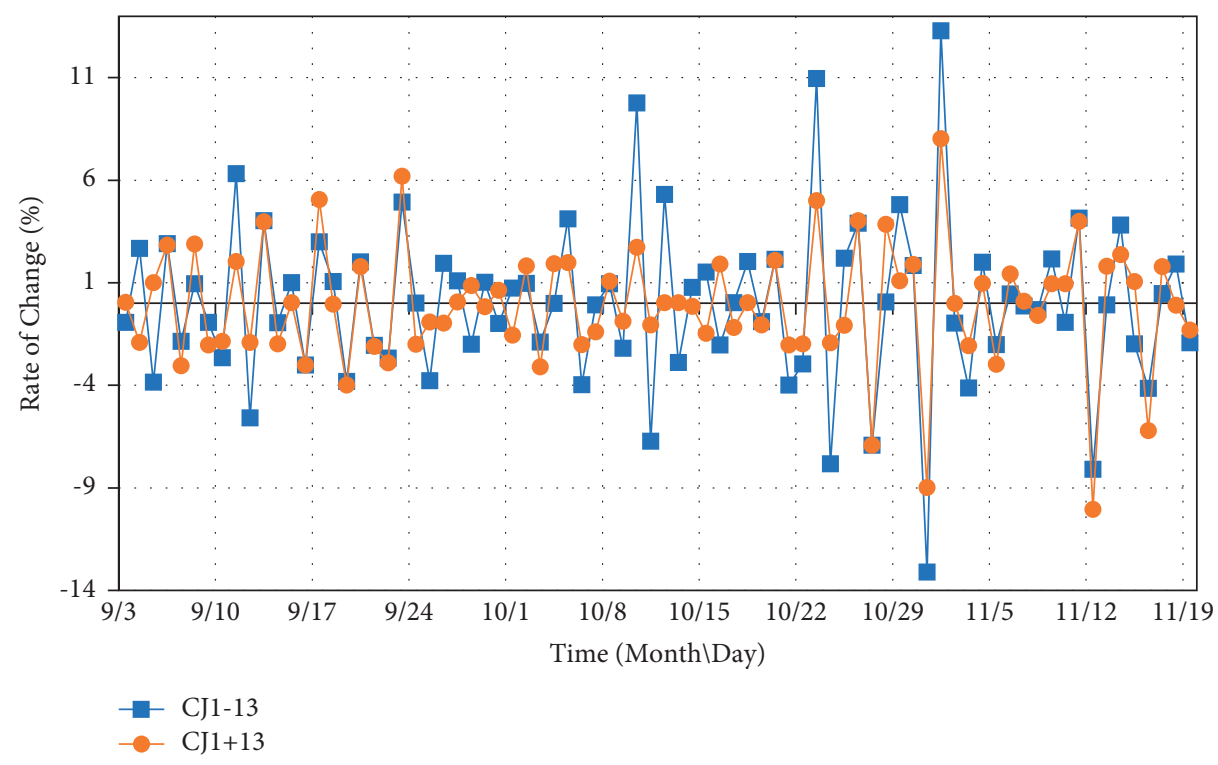

FIGURE 7: Rate of change of daily settlement (CJ1-13 and CJ1 +13).

an amount of $10 \mathrm{~mm}$. The maximum positive change of CJ14 settlement was 18.25 which occurred on November 8 , and the maximum negative change was -14.08 which occurred on November 7.

The maximum uplift of CJ1 + 4 occurred on November 30 , with a value of $7 \mathrm{~mm}$, and the maximum settlement occurred on November 7, with a value of $9 \mathrm{~mm}$. The largest positive change of CJ1 4 occurred on November 8 , with a change rate of 15.12, and the largest negative change occurred on November 7, with a change rate of -13.07 .

3.1.5. Comparative Analysis of CJ1-0, CJ1-9, and CJ1-17. It can be concluded from Figure 12 that the ground deformation amplitude, with the same distance from the jacking axis, tends to be the same. Therefore, we analyze the influence of jacking construction on the width direction, by comparing the ground deformation of CJ1-0, CJ1-9, and CJ1-17.

It can be seen from Figure 13 that CJ1-0 has the largest daily settlement and change rate, and CJ1-17 is the smallest of the three groups of data.

The maximum uplift of CJ1-0 occurred on November 30, with a value of $11 \mathrm{~mm}$, and the maximum settlement occurred on November 7 , with a value of $10 \mathrm{~mm}$. At the same time, the CJ1-0 had the largest positive change on November 8 , with a change rate of 17.24 , and had the largest negative change on September 27, with a change rate of -15.32 .

Theoretically, the ground settlement is mainly due to the fact that the support pressure of the excavation face is less 


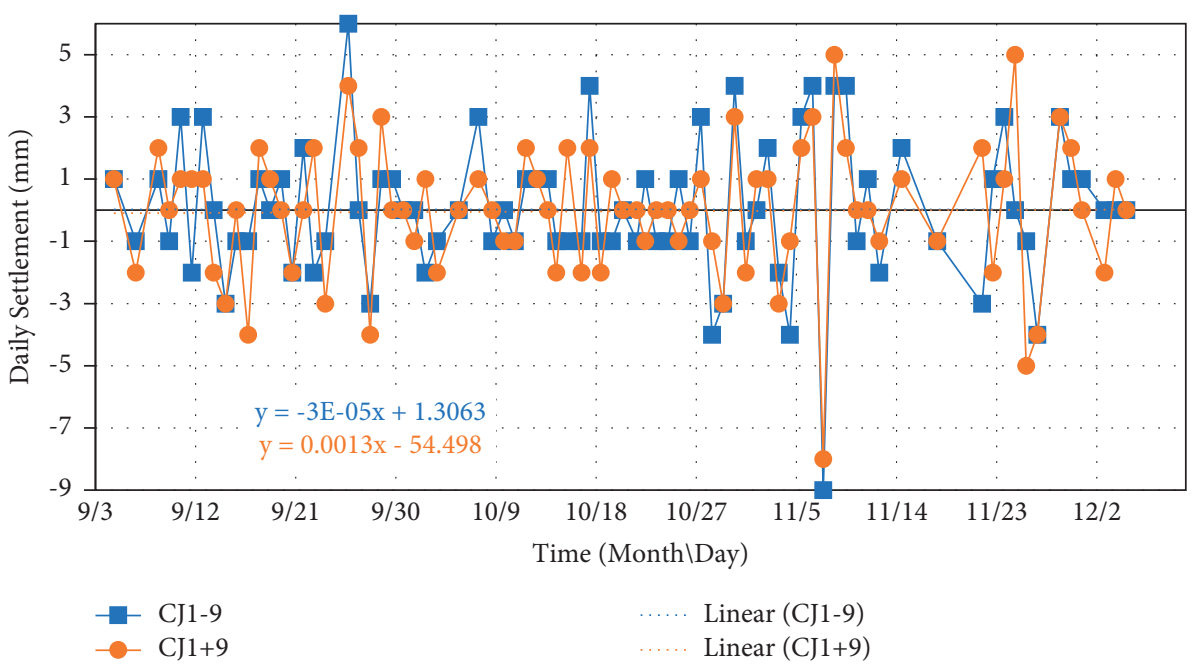

FIgURE 8: Daily settlement of CJ1-9 and CJ1 +9.

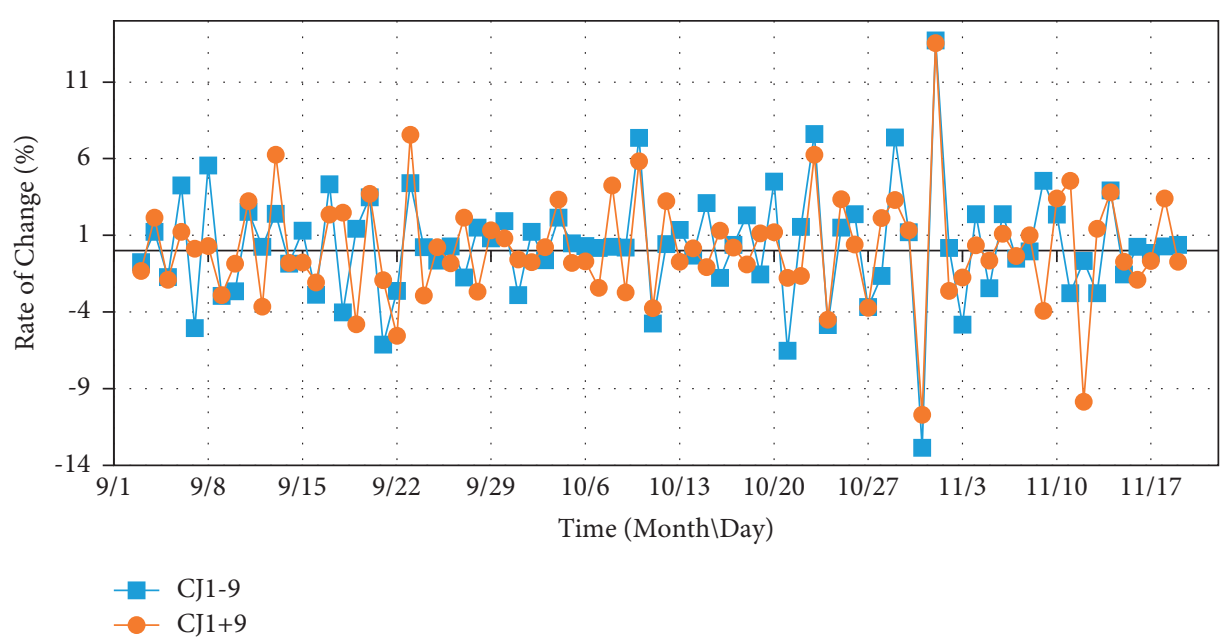

FIgURE 9: Rate of change of daily settlement (CJ1-9 and CJ1 +9).

than the active Earth pressure, and the ground uplift is generally related to the operation of synchronous grouting.

The monitoring points with equal distance from the jacking axis show similar rules under the influence of pipe jacking, which is mainly related to the attitude of pipe jacking, stratum parameters, ground buildings, and other factors.

The maximum uplift of monitoring points with the same distance from the axis does not occur on the same day, but the maximum settlement occurs on November 7 . The main reason is that the grouting was interrupted on November 7 and the ground subsided naturally. The mud was injected on November 8 , so the measuring point had a sharp increase. The daily deformation will fluctuate repeatedly between uplift and settlement, which is the result of synchronous grouting and deviation correction operation.

3.2. Vertical Cumulative Settlement. The longitudinal cumulative settlement value of the axis caused by pipe jacking shows roughly the same rule at the monitoring points on both sides of the axis. Therefore, the observation points on the south side of the jacking axis are used as the research object to analyze the longitudinal cumulative settlement of the surface. The selection of measuring points for CJ1, CJ2, and CJ3 sections is demonstrated in Figures 14-16.

As is shown in Figure 14, when the top of the pipe jacking cutter head is at a certain distance from the CJ1 section, the monitoring section has a certain degree of settlement. The main reason is that the original Earth pressure balance is broken during the jacking process and there is no simultaneous grouting supplement, which in turn causes a certain degree of surface settlement. As there are many key buildings distributed around the CJ1 section, the settlement control is the most stringent among the other two sections. Several measures are adopted during the jacking process such as adjustment of muddy water pressure and synchronous grouting pressure, to control the surface settlement value below $2.0 \mathrm{~cm}$.

Similarly, before the jacking pipe crosses the CJ2 and CJ3 sections, a certain degree of ground subsidence also occurs 


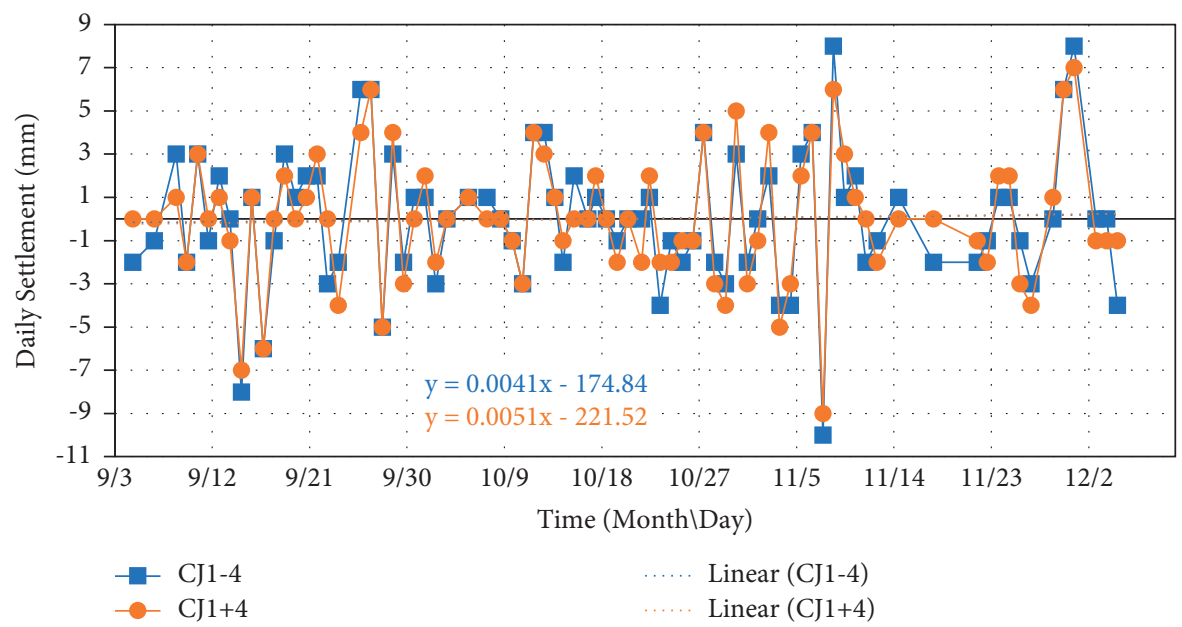

FIgURE 10: Daily settlement of CJ1-4 and CJ1 +4 .

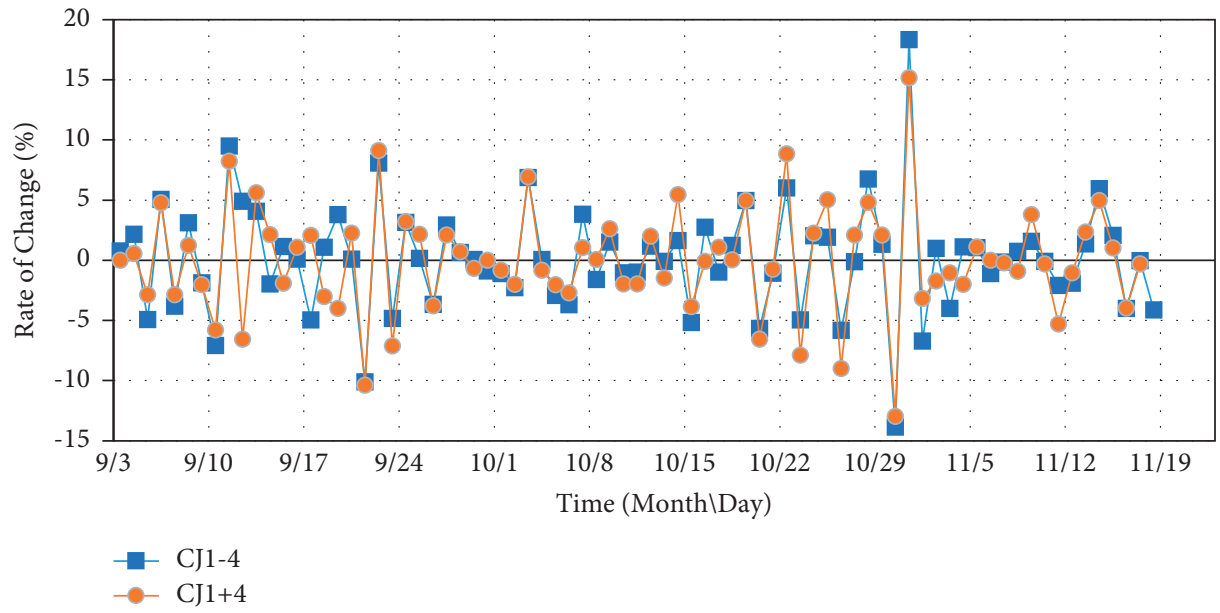

FIgURE 11: Rate of change of daily settlement (CJ1-4 and CJ1 + 4).

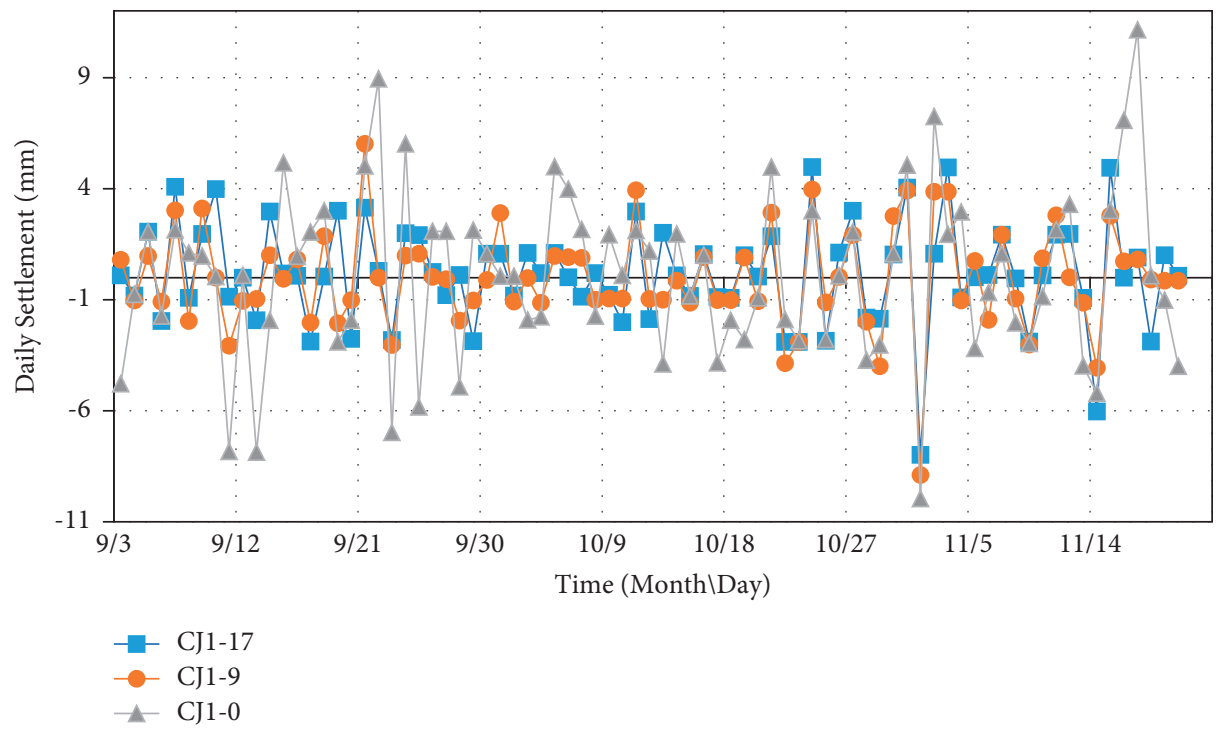

Figure 12: Daily settlement of CJ1-17, CJ1-9, and CJ1-0. 


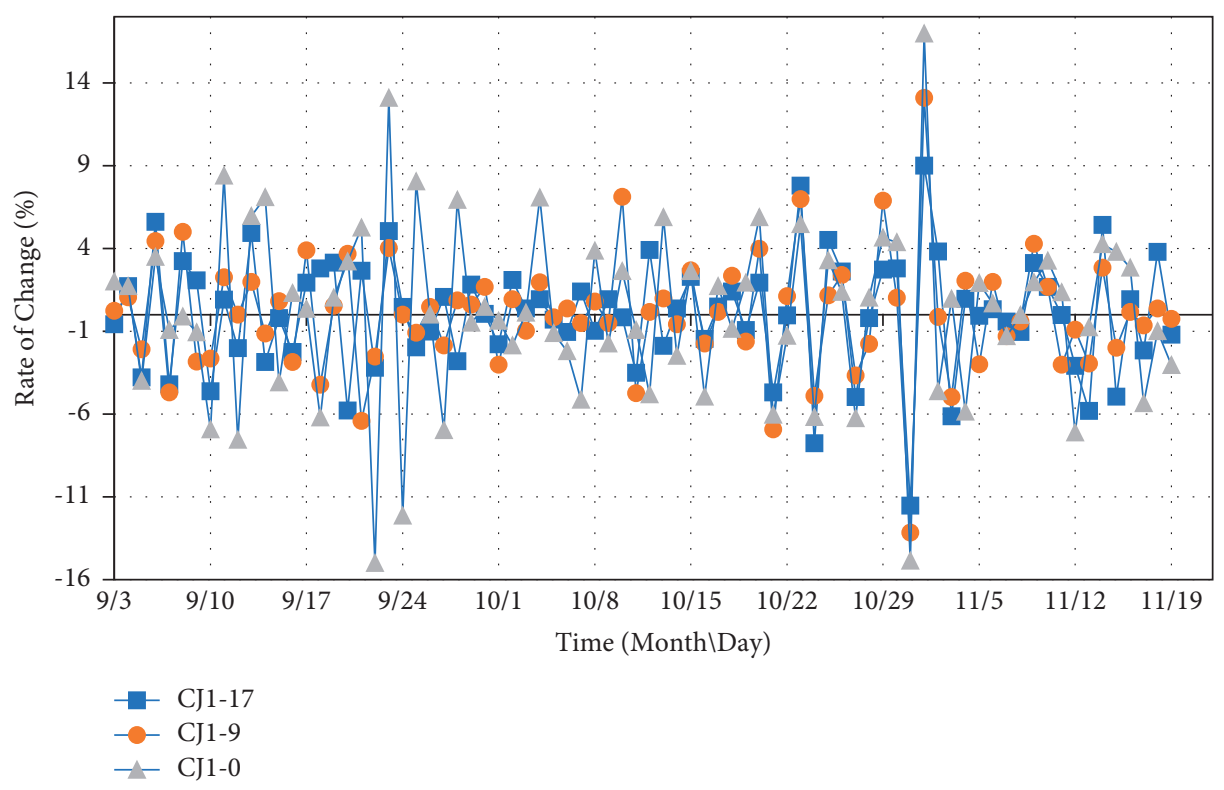

FIgURE 13: Rate of change of daily settlement (CJ1-17, CJ1-9, and CJ1-0).

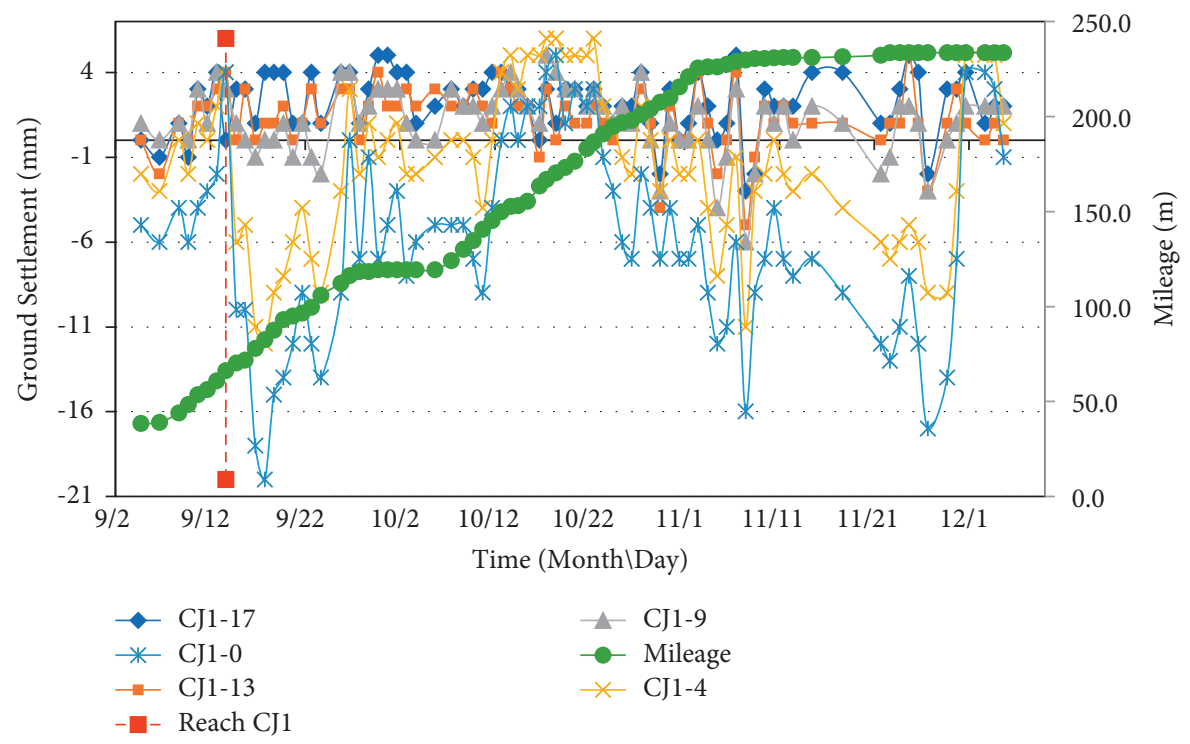

Figure 14: Cumulative settlement of CJ1.

for the same reason as the CJ1 section. After the pipe jacking equipment was pushed into the monitoring section, the settlement values of the three monitoring sections increased significantly, but with the increase of the jacking length, the settlement observation value gradually stabilized with the CJ3 section being the most obvious. In addition, the settlement deformation of the measurement points on each section shows a similar overall law. The jacking construction has a greater impact on the measurement points which are closer to the axis, especially the one on the axis. Due to the superimposed effect of groundwater loss, synchronous grouting pressure adjustment, pipe jacking posture adjustment, and other factors, it shows some certain irregularities.

Finally, it should be noted that since the CJ3 section is close to the river, grouting construction should be minimized considering environmental protection and safety issues, and thus, the settlement law of this section is closer to natural settlement.

3.3. Horizontal Settlement Trough. To analyze the settlement troughs of the three monitoring sections, five time points are selected for each settlement trough. The observation results are shown in the following figures.

It can be seen from Figure 17 that although the settlement observation data of the CJ1 section fluctuates greatly and the settlement trough curve is relatively twisting, the settlement deformations of the three monitoring sections basically indicate a symmetrical distribution. In addition, after the pipe jacking equipment was pushed to the 


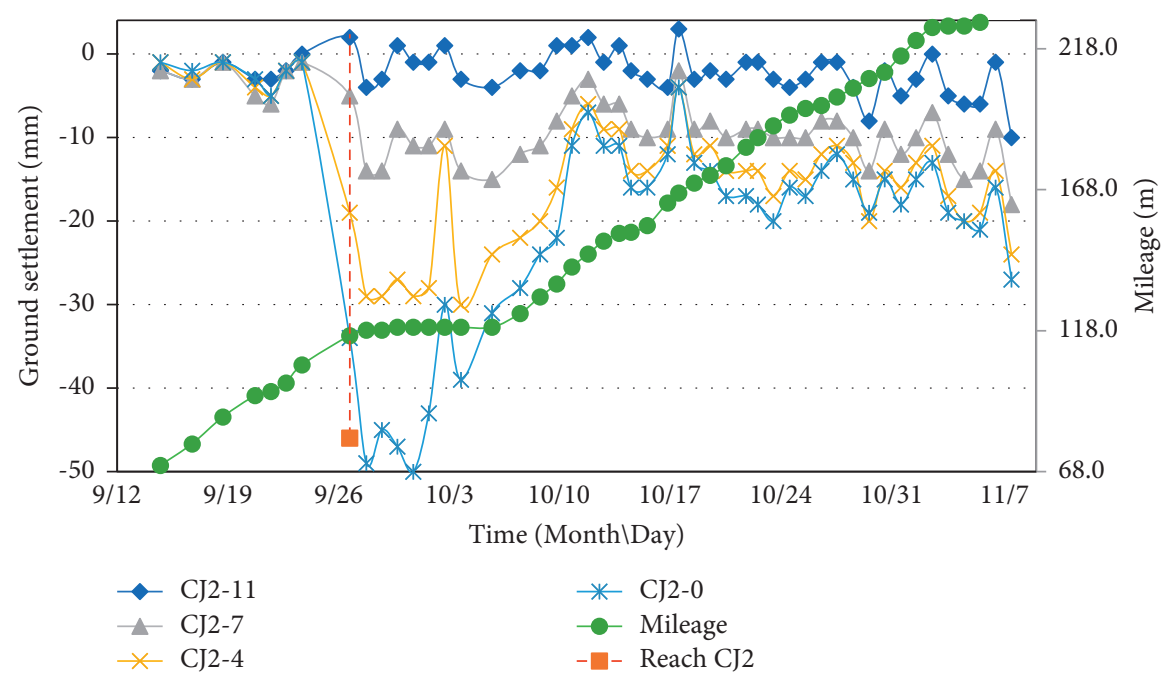

Figure 15: Cumulative settlement of CJ2.

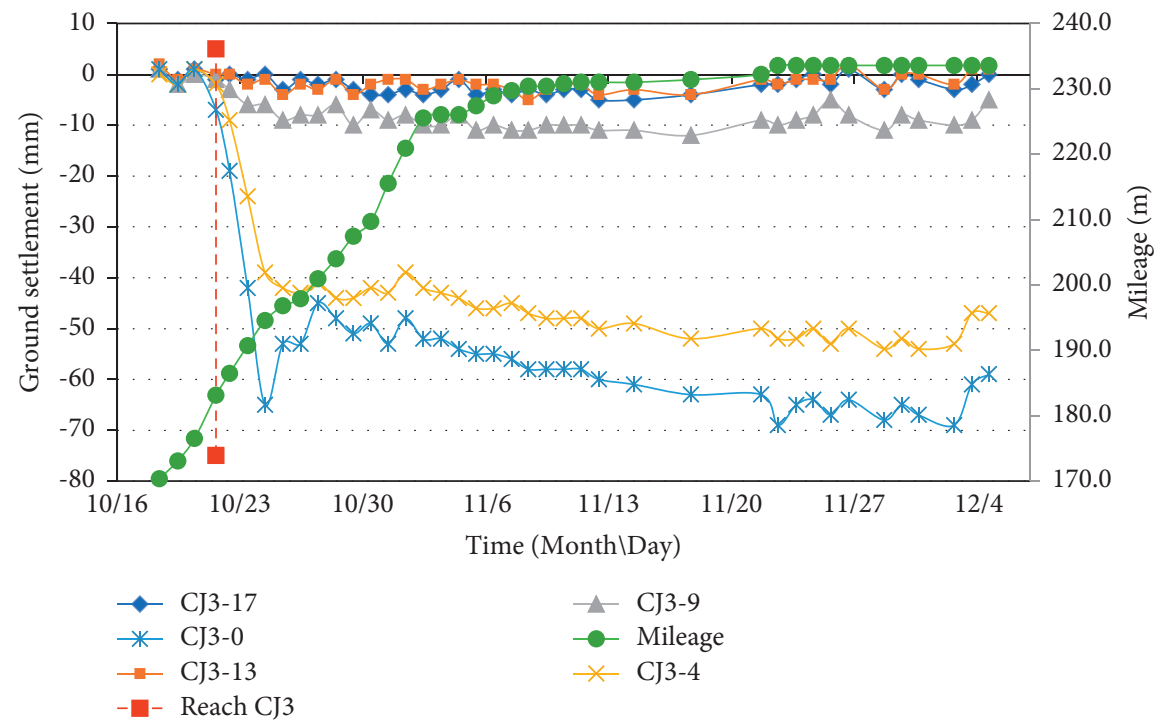

Figure 16: Cumulative settlement of CJ3.

monitoring section, the settlement deformation increased significantly. However, with the passage of time, the curve of the cross-section settlement groove gradually becomes smooth, and the deformation of the cross section gradually decreases. The maximum settlement deformation point of the three settlement trough curves occurs on the axis of the jacking pipe and only the CJ3 section has a numerical rate on the axis less than on both sides of the axis during the passage of the pipe jacking machine which is related to the sole grouting at the top of the pipe jacking during the river crossing; in addition, as time goes by and the distance of the jacking section becomes farther and farther from the section, the influence of jacking on settlement becomes smaller and smaller, and the influence of pipe jacking on settlement decreases as the distance from the axis of the jacking pipe increases.
Regarding the CJ1 section, due to the adjustment of the synchronous grouting parameters, the settlement trough curve fluctuates greatly, and the law is not obvious; at the CJ2 section, stable synchronous grouting process parameters have been explored: with the passage of time and the progress of simultaneous grouting, the deformation of the section changes from settlement to elevation, which also shows that the selection of simultaneous grouting parameters is reasonable; and finally, because the CJ3 section is close to the river and only grouted at the top of the pipe gallery during the jacking period, the subsequent settlement deformation tends to increase slowly but eventually is close to a stable state. In the three sections, the CJ3 monitoring section is relatively less affected by construction factors and basically reflects the natural settlement trend and law of surrounding rocks during pipe jacking. The next stage of 
theoretical analysis will focus on the research and analysis of the CJ3 section data.

\section{Theoretical Analysis of Ground Settlement}

4.1. Peek Curve. The Peck formula [10] currently is one of the prediction models that is widely used in soil deformation caused by pipe jacking construction. The formula for estimating horizontal ground settlement is

$$
\begin{aligned}
& S(x)=S_{\max } e^{-x^{2} / 2 i^{2}}, \\
& S_{\max }=\frac{V_{\text {loss }}}{i \sqrt{2 \pi}}
\end{aligned}
$$

where $S_{(x)}$ is the Land settlement $(\mathrm{m}), x$ is the horizontal distance from the tunnel axis $(\mathrm{m}), S_{\max }$ is the maximum ground settlement above the tunnel axis $(\mathrm{m})$, the $V_{\text {loss }}$ is the amount of soil loss per unit length of the tunnel $\left(\mathrm{m}^{3} / \mathrm{m}\right)$, and $i$ is the Width coefficient of ground settlement trough $(\mathrm{m})$.

According to O'Reilly and New's experience in London, there is a simple linear relationship between $i$ and $z_{0}$ (tunnel axis depth):

$$
i=K z_{0}
$$

where $K$ is the trough width parameter depending on the nature of the land.

Combined with the construction data of underground projects in Shanghai [8], the recommended value of the trough width parameter is 0.5 . The determination of the soil loss per unit length of the pipe jacking $V_{\text {loss }}$ is calculated by the empirical method:

$$
V_{\text {loss }}=l h \eta,
$$

where $l$ is the width of the tunnel, $h$ is the height of the tunnel, and $\eta$ is the ground loss ratio (see Table 4 ).

According to the design, $h=5.5 \mathrm{~m}, l=9.1 \mathrm{~m}, K=0.5$, $z_{0}=11.75 \mathrm{~m}$, and take $\eta=2.5 \%$, and substitute them into the empirical method, respectively, obtaining $i=5.9 \mathrm{~m}$, $V_{\text {loss }}=1.25 \mathrm{~m}^{3} / \mathrm{m}$, and $S_{\max }=0.09 \mathrm{~m}$. In addition, the width of the settlement tank can be calculated which is 2.1.

4.2. Random Medium Theory. According to the random medium theory, the settlement of a certain point caused by jacking is a random event, and it is the superposition of infinite small excavations. The rise or sink of the soil in the disturbance zone around the pipe gallery $W(X, Z)$ is expressed by

$$
W(X, Z)=(n-1) \iint_{\Omega} \frac{\tan \beta}{(\eta-Z)} \bullet \exp \left\{-\frac{\pi}{(\eta-Z)^{2}} \tan \beta^{2}(X-\xi)^{2}\right\} \mathrm{d} \xi \mathrm{d} \eta
$$

where $\Omega$ is the area of the tunnel excavation in pipe jacking construction, $\beta$ is the major influence angle of the surrounding rock in the upper part of the tunnel, $\varphi$ is the angle of internal friction, and $(n-1)$ is the ground loss rate.
When the pipe jacking excavation surface is rectangular, suppose that the tunnel excavation width is $s$ and the excavation height is $h$, then $\Omega=s h$, and the distance between the center of the tunnel and the ground surface is $H$; then, the above formula (4) is

$$
W(X, Z)=(n-1) \int_{-2 / 2}^{s / 2} \int_{H-h / 2}^{H+h / 2} \frac{\tan \beta}{(\eta-Z)} \cdot \exp \left\{-\frac{\pi}{(\eta-Z)^{2}} \tan \beta^{2}(X-\xi)^{2}\right\} \mathrm{d} \xi \mathrm{d} \eta
$$

The stratum above the pipe jacking machine at the CJ3 section is (1)-5, (4), (5), (6)-1, (6)-2, and the thickness is $1.4 \mathrm{~m}$, $3.5 \mathrm{~m}, 1.5 \mathrm{~m}, 1.3 \mathrm{~m}$, and $6.8 \mathrm{~m}$, respectively. By referring to Table 1 for information about stratum physical and mechanics, the internal friction angles of each soil layer are $16.8,15.7,22.7,31.4$, and 33.4 successively. The average friction angle $\varphi$ of the CJ3 section is calculated as follows:

$$
\varphi=\frac{1.4 \times 16.8+3.5 \times 15.7+1.5 \times 22.7+1.3 \times 31.4+6.8 \times 33.4}{14.5}=26.24
$$

In addition, taking $n$ as 1.25 and combining it with the above formula, the width of the settlement tank is $24.3 \mathrm{~m}$.

4.3. Settlement Curve. We select the measured data of the maximum settlement at the CJ3 section and use the
MATLAB 9.0 combined with the Peck formula and the random medium theory to express the monitoring data in the same coordinate system, as shown in Figure 18.

As shown in Figure 18, outside the width of the rectangular pipe jacking, the curve obtained by the random medium theory 


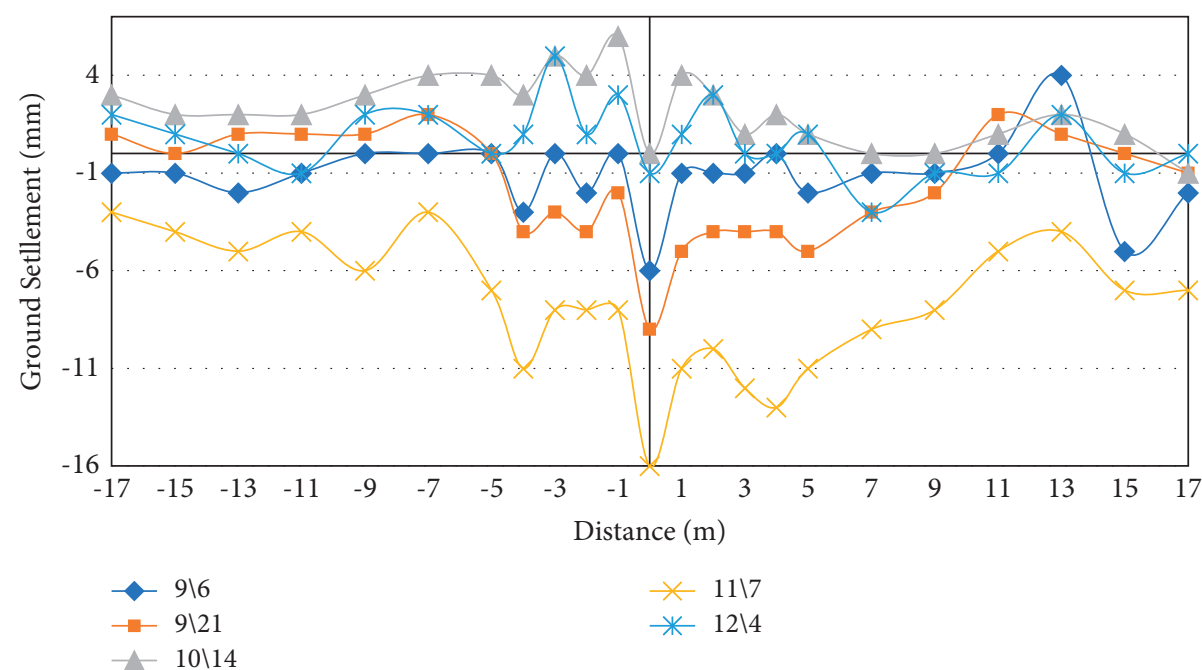

(a)

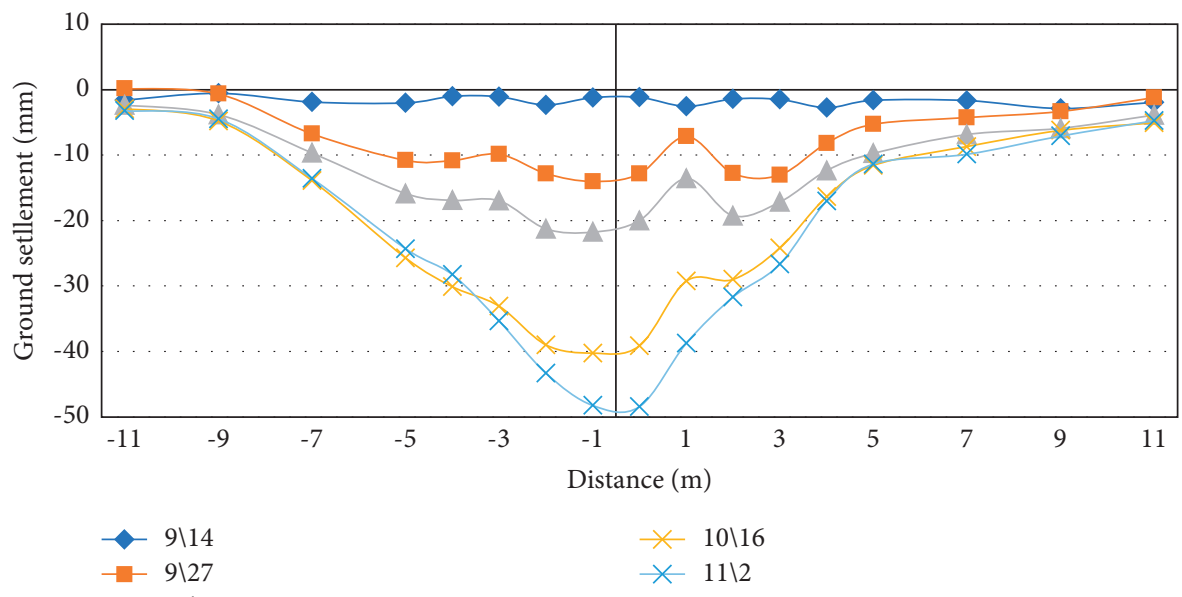

(b)

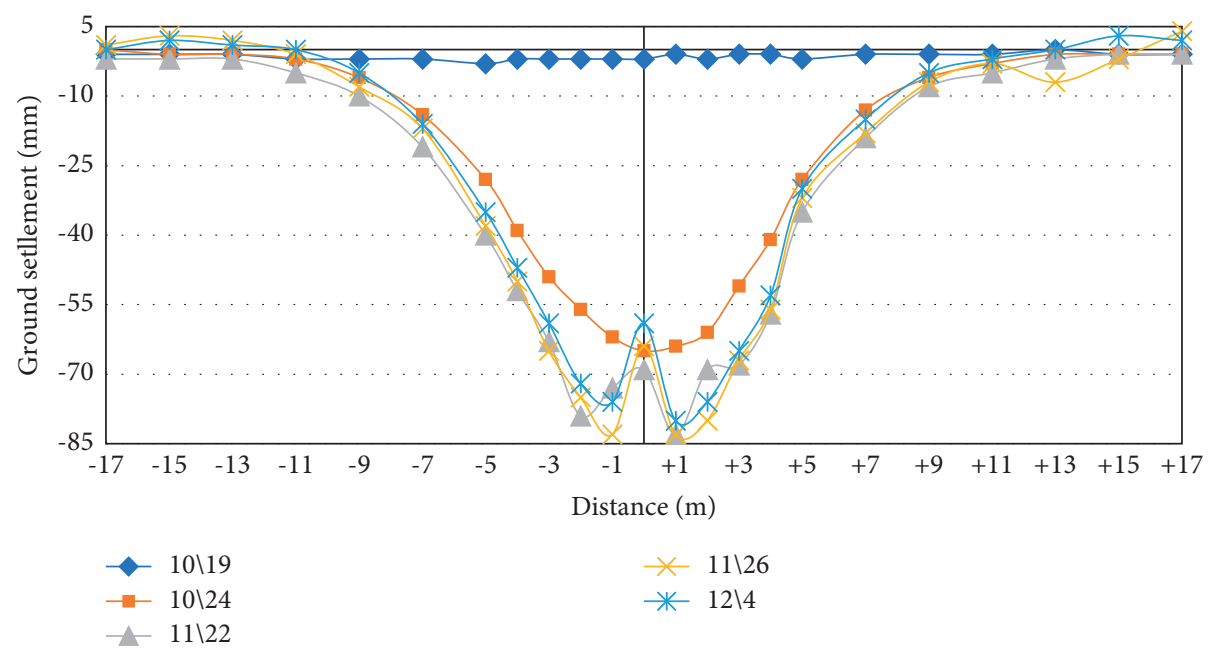

(c)

FIgURE 17: Curves of surface settlement trough. (a) CJ1; (b) CJ2; (c) CJ3.

better fits the actual measured value, especially achieving a high degree of fitting at the two ends of the axis; but within the width range, the soil settlement obtained by the random medium theory is obviously larger than the actual measured value, while the settlement value obtained by the Peck curve is closer to the measured value. 
TABle 4: Empirical values for ground loss ratios.

\begin{tabular}{lccc}
\hline Types of soil & Ground loss ratio $\eta(\%)$ & Types of soil & Ground loss ratio $\eta(\%)$ \\
\hline Clayey soil & $0.5 \sim 2.5$ & Newly deposited silty clay & $2 \sim 10$ \\
Hard clay & $1 \sim 2$ & Noncohesive soil (above groundwater level) & $2 \sim 5$ \\
Icy soil (without atmospheric pressure) & $2 \sim 2.5$ & Noncohesive soil & $2 \sim 10$ \\
Icy soil (with atmospheric pressure) & $1 \sim 1.5$ & (below the groundwater level) & Artificial fill \\
\hline
\end{tabular}

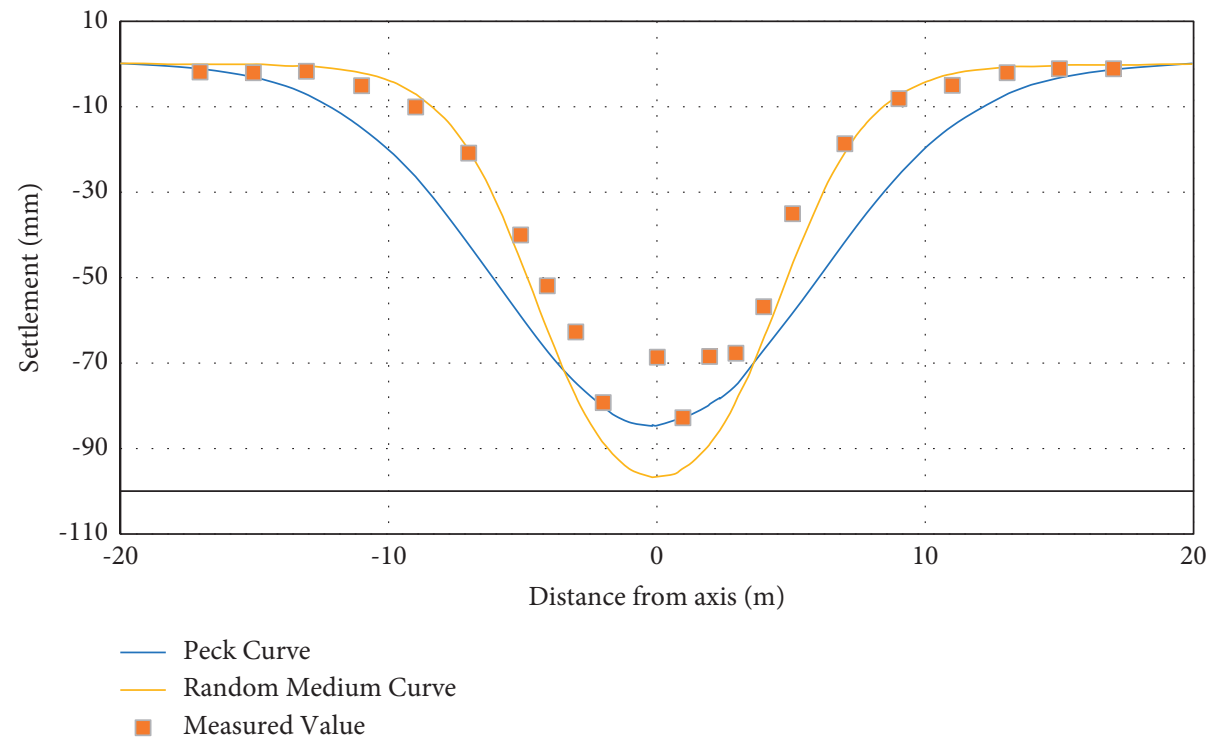

FiguRE 18: Comparison between calculated and observed results of CJ3's settlement.

In the process of pipe jacking construction, the vicinity of the axis is more impacted by construction parameters, such as jacking mud pressure, jacking speed, simultaneous grouting, and thixotropic mud. As the random medium analysis theory is based on the superposition principle for theoretical analysis, its adaptability to complex and changeable site construction parameters is poor. Therefore, the random medium theory has a better performance in the prediction of the area that is farther from the pipe jacking range.

According to the Peck formula, the parameters of the Peck formula adopt the recommended values, so the theoretical values outside the jacking width are quite different from the measured values [36-43]. Due to the above reasons, we use MATLAB 9.0 to fit the measured data and get the fitting Peak curve.

The fitting formula: $S(x)=-79.23 \exp \left(-x^{2} / 37.87\right)$ (mm)

Width coefficient of surface settlement trough: $i=\sqrt{37.87 / 2}=4.35$

Ground loss: $\quad V_{\text {loss }}=S_{\max } \sqrt{2 \pi i}=79.23 / 1000 \times$ $\sqrt{2 \pi \times 4.35}=0.414$

Soil loss: $n=V_{\text {loss }} / l h=0.414 /(9.1 \times 5.5)=0.8 \%$

According to O'Reilly and New [8], there is a multiple relationship between the width and the width coefficient of surface settlement trough. The width of the settlement trough is $6 i$, which means the horizontal distance from the jacking axis is $3 i$. Therefore, the settlement trough width of this project is $26.1 \mathrm{~m}$ (which is closer to $24.3 \mathrm{~m}$ obtained by the random medium method) by using the fitting Peck curve. It can be concluded that the ground loss rate based on the empirical recommended value is too large, which leads to inaccurate prediction and the modified Peck formula is more accurate than the measured value.

The modified Peck prediction diagram, random medium curve diagram, and cumulative maximum settlement diagram of CJ1 and CJ2 section are shown in Figure 19. It can be seen from Figure 19 that the settlement of CJ1 and CJ2 is quite different from the fitted Peck curve and random medium curve. Among the three monitoring sections, the maximum settlement occurs in the CJ3 section, with a value of $85 \mathrm{~mm}$. However, the maximum settlement of CJ1 sections is reduced to $16 \mathrm{~mm}$ through synchronous grouting. The Peek curve and random medium theory are suitable for the law of natural settlement because they do not consider too much the construction factors. CJ1 and CJ2 are especially affected by grouting, so they can not show the law of the CJ3 section. As the CJ1 section is closer to the building, stronger grouting measures are taken than CJ2, and the settlement value of the CJ1 section is also smaller than CJ2. In other words, grouting also makes the settlement value of most monitoring points controlled below the settlement curve, which is one of the effective means to reduce land settlement. 


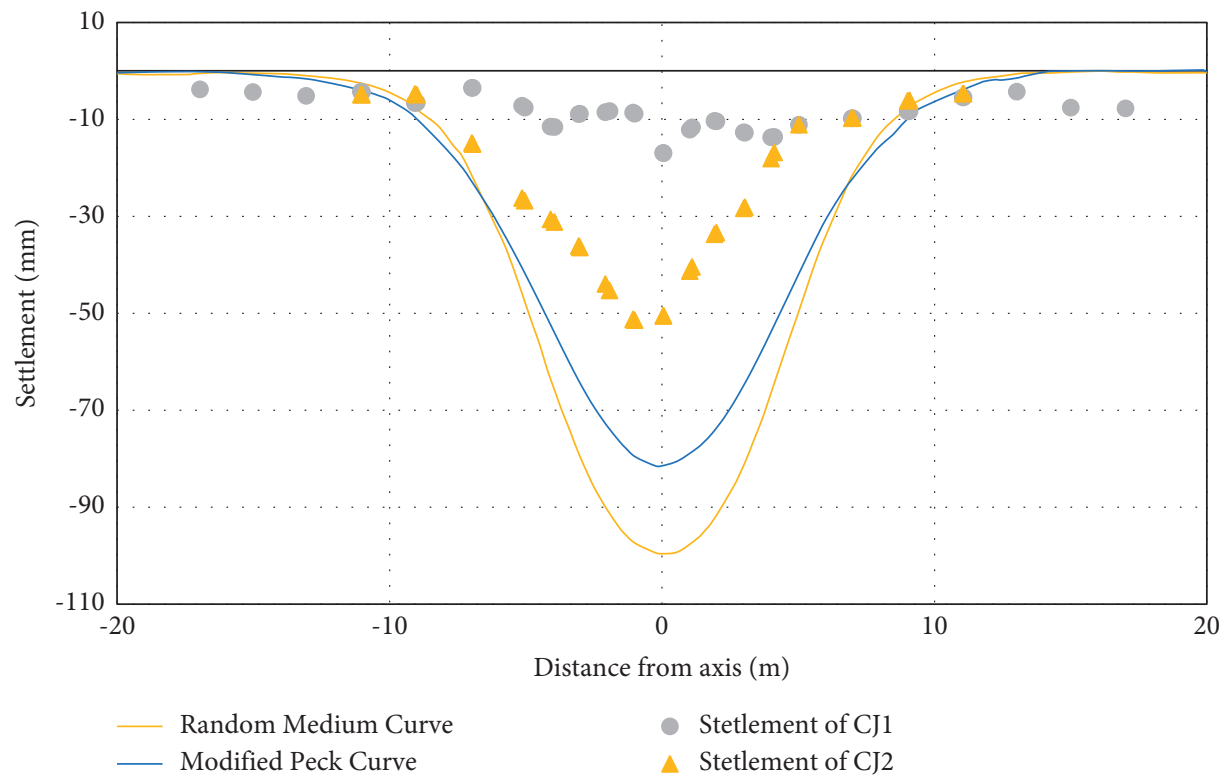

FIgure 19: Modified Peck curve, random medium curve, and cumulative maximum settlement (CJ1, CJ2).

In a word, for similar projects crossing silty sand stratum, the modified formula can be used in the construction site to predict the surface settlement and determine the influence range of surface settlement. Grouting treatment can be used to prevent excessive surface settlement in the process of jacking.

\section{Conclusion}

The soil settlement caused by the rectangular pipe jacking in silt formations is fundamentally distributed on both sides of the jacking axis in a symmetric way, and the impact of jacking construction decreases as the distance from the axis point increases.

For the pipe jacking width range with a large settlement value, the Peck formula can be used for accurate prediction without the influence of construction technology such as reinforcement grouting. However, both the Peck formula and the random medium theory do not consider the influence of construction parameters, so neither of them can perform a perfect analysis of the fullface settlement analysis caused by the rectangular jacking pipe in the silt formation, and more in-depth research is needed.

From the actual measured data, the surface settlement width caused by jacking is about 1.5 times the width of the jacking pipe, and the grouting reinforcement during jacking has a huge impact on the fluctuation of the settlement value. In addition, the settlement of the modified Peck formula is the largest, followed by random medium theory. The settlement values of CJ1 and CJ2 are smaller than the theoretical prediction value, so it is also proved that the selected construction technology can effectively reduce the land settlement. Therefore, prereinforcement must be carried out before the pipe jacking passes through the key buildings, with the purpose of reducing the impact of various auxiliary processes during construction.

\section{Data Availability}

The data that support the findings of this study are available from the corresponding author upon reasonable request.

\section{Conflicts of Interest}

The authors declare no potential conflicts of interest with respect to the research, regarding the publication of this paper, authorship, and publication of this article.

\section{Acknowledgments}

This research was supported by the National Natural Science Foundation of China (No. 51578253) and Science and Technology Guiding Project of Fujian Province (No. 2020Y0087).

\section{References}

[1] O. Demeijer, J. J. Chen, M. G. Li, and J. H. Wang, "Influence of passively loaded piles on excavation-induced diaphragm wall displacements and ground settlements," International Journal of Geomechanics, vol. 18, no. 6, Article ID 04018052, 2017.

[2] K. Elbaz, S.-L. Shen, W.-C. Cheng, and A. Arulrajah, "Cutter-disc consumption during earth pressure balance tunnelling in mixed strata," Proceedings of the Institution of Civil Engineers-Geotechnical Engineering, vol. 171, no. 4, pp. 363-376, 2018.

[3] K. Shou, J. Yen, and M. Liu, "On the frictional property of lubricants and its impact on jacking force and soil-pipe interaction of pipe-jacking," Tunnelling and Underground Space Technology, vol. 25, no. 4, pp. 469-477, 2010.

[4] X. Cai, Z. Zhou, H. Zang, and Z. Song, "Water saturation effects on dynamic behavior and microstructure damage of 
sandstone: phenomena and mechanisms," Engineering Geology, vol. 276, Article ID 105760, 2020.

[5] Z. Zhou, X. Cai, X. Li, W. Cao, and X. Du, "Dynamic response and energy evolution of sandstone under coupled static-dynamic compression: insights from experimental study into deep rock engineering applications," Rock Mechanics and Rock Engineering, vol. 53, no. 3, pp. 1305-1331, 2020.

[6] X. Cai, Z. Zhou, and X. Du, "Water-induced variations in dynamic behavior and failure characteristics of sandstone subjected to simulated geo-stress," International Journal of Rock Mechanics and Mining Sciences, vol. 130, Article ID 104339, 2020.

[7] D.-J. Ren, Y.-S. Xu, J. Shen, A. Zhou, and A. Arulrajah, "Prediction of ground deformation during pipe-jacking considering multiple factors," Applied Sciences, vol. 8, no. 7, Article ID 8071051, 2018.

[8] K. M. Lee, H. W. Ji, C. K. Shen, J. H. Liu, and T. H. Bai, "Ground response to the construction of Shanghai metro tunnel-line 2," Soils and Foundations, vol. 39, no. 3, pp. 113-134, 1999.

[9] Z. Niu, Y. Cheng, Y. Zhang, Z. Song, G. Yang, and H. Li, “A new method for predicting ground settlement induced by pipe jacking construction," Mathematical Problems in Engineering, vol. 2020, Article ID 1681347, 11 pages, 2020.

[10] R. B. Peck, "Deep excavations and tunneling in soft ground," in Proceedings of the 7th ICSMFE, Balkema, Rotterdam, 1969.

[11] M. P. O'Reilly and B. M. New, "Settlements above tunnels in the United Kingdom - their magnitude and prediction," in Proceedings of the Tunnelling, Institution of Mining and Metallurgy, pp. 173-181, London, UK, 1982.

[12] N. Loganathan and H. G. Poulos, "Analytical prediction for tunneling-induced ground movements in clays," Journal of Geotechnical and Geoenvironmental Engineering, vol. 124, no. 9, pp. 846-856, 1998.

[13] P. B. Attewell and I. W. Farmer, "Ground settlement above shield driven tunnels in clay," International Journal of Rock Mechanics and Mining Science \& Geomechanics Abstracts, vol. 12 , no. 4 , p. $61,1975$.

[14] B. C. Liu and J. S. Zhang, "Stochastic method for ground subsidence due to near surface excavation," Chinese Journal of Rock Mechanics and Engineering, vol. 14, no. 4, pp. 289-296, 1995, In Chinese.

[15] J. Litwiniszyn, "Application of the equation of stochastic processes to mechanics of loose bodies," Archives of $\mathrm{Me}$ chanics, vol. 8, no. 4, pp. 393-411, 1956.

[16] C. Sagaseta, "Analysis of undraind soil deformation due to ground loss," Géotechnique, vol. 37, no. 3, pp. 301-320, 1987.

[17] A. Verruijt and J. R. Booker, "Surface settlements due to deformation of a tunnel in an elastic half plane," Géotechnique, vol. 46, no. 4, pp. 753-756, 1996.

[18] J. Qiu, Y. Lu, J. Lai, Y. Zhang, T. Yang, and K. Wang, "Experimental study on the effect of water gushing on loess metro tunnel," Environmental Earth Sciences, vol. 79, no. 11, Article ID 261(2020), 2020.

[19] D.-J. Ren, S.-L. Shen, A. Arulrajah, and H.-N. Wu, "Evaluation of ground loss ratio with moving trajectories induced in double-O-tube (DOT) tunnelling," Canadian Geotechnical Journal, vol. 55, no. 6, pp. 894-902, 2018.

[20] W.-C. Cheng, J. C. Ni, J. S.-L. Shen, and H.-W. Huang, "Investigation into factors affecting jacking force: a case study," Proceedings of the Institution of Civil Engineers-Geotechnical Engineering, vol. 170, no. 4, pp. 322-334, 2017.

[21] F. Li, K. Fang, and H. Li, "Application of ANSYS 3D FEM in studies of surface deformation caused by pipe jacking,"
Wuhan University Journal of Natural Sciences, vol. 12, no. 4, pp. 633-637, 2007.

[22] D. Zhang, B. Liu, and Y. Qin, "Construction of a large-section long pedestrian underpass using pipe jacking in muddy silty clay: a case study," Tunnelling and Underground Space Technology, vol. 60, pp. 151-164, 2016.

[23] H. Shimada, S. Khazaei, and K. Matsui, "Small diameter tunnel excavation method using slurry pipe-jacking," Geotechnical \& Geological Engineering, vol. 22, no. 2, pp. 161-186, 2004.

[24] H. Shimada, T. Sasaoka, S. Khazaei, Y. Yoshida, and K. Matsui, "Performance of mortar and chemical grout injection into surrounding soil when slurry pipe-jacking method is used," Geotechnical \& Geological Engineering, vol. 24, no. 1, pp. 57-77, 2006.

[25] T. Kasper and G. Meschke, "On the influence of face pressure, grouting pressure and TBM design in soft ground tunnelling," Tunnelling and Underground Space Technology, vol. 21, no. 2, pp. 160-171, 2006.

[26] F. J. Bing, X. Wang, N. Xi, and L. Fang, "3D numerical simulation of pipe jacking and its soil applicability study," Chinese Journal of Underground Space and Engineering, vol. 7, no. 6, pp. 1209-1215, 2011, in Chinese.

[27] J. X. Tang, L. S. Wang, C. Ji, and X. Y. Kou, "Three-dimensional numerical analysis of ground deformation induced by quasi rectangle EPB shield tunneling," Journal of East China Jiaotong University, vol. 1, no. 33, pp. 9-15, 2016, in Chinese.

[28] S. Zhou, Y. Wang, and X. Huang, "Experimental study on the effect of injecting slurry inside a jacking pipe tunnel in silt stratum," Tunnelling and Underground Space Technology, vol. 24, no. 4, pp. 466-471, 2009.

[29] X. Yang, Y. Liu, and C. Yang, "Research on the slurry for longdistance large-diameter pipe jacking in expansive soil," $A d$ vances in Civil Engineering, vol. 2018, Article ID 9040471, 9 pages, 2018.

[30] Y. Sun, F. Wu, W. J. Sun, H. M. Li, and G. J. Shao, "Two underground pedestrian passages using pipe jacking: case study," Journal of Geotechnical and Geoenvironmental Engineering, vol. 145, no. 2, Article ID 05018004, 2019.

[31] P. Zhang, S. S. Behbahani, B. Ma, T. Iseley, and L. Tan, “A jacking force study of curved steel pipe roof in Gongbei tunnel: calculation review and monitoring data analysis," Tunnelling and Underground Space Technology, vol. 72, pp. 305-322, 2018.

[32] C. Li, Z. Zhong, C. Bie, and X. Liu, "Field performance of large section concrete pipes cracking during jacking in Chongqing a case study," Tunnelling and Underground Space Technology, vol. 82, pp. 568-583, 2018.

[33] A. W. Stuedlein and T. Meskele, "Preliminary design and engineering of pipe ramming installations," Journal of Pipeline Systems Engineering and Practice, vol. 3, no. 4, pp. 125-134, 2012.

[34] X. Cai, Z. Zhou, L. Tan, H. Zang, and Z. Song, "Water saturation effects on thermal infrared radiation features of rock materials during deformation and fracturing," Rock Mechanics and Rock Engineering, vol. 53, no. 11, pp. 4839-4856, 2020.

[35] X. Cai, Z. Zhou, L. Tan, H. Zang, and Z. Song, "Fracture behavior and damage mechanisms of sandstone subjected to wetting-drying cycles," Engineering Fracture Mechanics, vol. 234, Article ID 107109, 2020.

[36] Z. Leng, Y. Fan, Q. Gao, and Y. Hu, "Evaluation and optimization of blasting approaches to reducing oversize boulders 
and toes in open-pit mine," International Journal of Mining Science and Technology, vol. 30, no. 3, pp. 373-380, 2020.

[37] I. Vennes, H. Mitri, D. R. Chinnasane, and M. Yao, "Largescale destress blasting for seismicity control in hard rock mines: a case study," International Journal of Mining Science and Technology, vol. 30, no. 2, pp. 141-149, 2020.

[38] A. I. Lawal, S. Kwon, O. S. Hammed, and M. A. Idris, "Blastinduced ground vibration prediction in granite quarries: an application of gene expression programming, ANFIS, and sine cosine algorithm optimized ANN," International Journal of Mining Science and Technology, vol. 31, no. 2, pp. 265-277, 2021.

[39] X. Liu, S. Song, Y. Tan et al., "Similar simulation study on the deformation and failure of surrounding rock of a large section chamber group under dynamic loading," International Journal of Mining Science and Technology, vol. 31, no. 3, pp. 495-505, 2021.

[40] R. Kumar, P. K. Mandal, A. Narayan, and A. J. Das, "Evaluation of load transfer mechanism under axial loads in a novel coupler of dual height rock bolts," International Journal of Mining Science and Technology, vol. 31, no. 2, pp. 225-232, 2021.

[41] Y. Zhou, D. Zhao, B. Li, H. Wang, Q. Tang, and Z. Zhang, "Fatigue damage mechanism and deformation behaviour of granite under ultrahigh-frequency cyclic loading conditions," Rock Mechanics and Rock Engineering, vol. 54, no. 9, pp. 4723-4739, 2021.

[42] Y. G. Zhang, Y. L. Xie, Y. Zhang, J. B. Qiu, and S. X. Wu, "The adoption of deep neural network (DNN) to the prediction of soil liquefaction based on shear wave velocity," Bulletin of Engineering Geology and the Environment, vol. 80, no. 6, pp. 5053-5060.

[43] J. Ma, X. L. Li, J. G. Wang et al., "Experimental study on vibration reduction technology of hole-by-hole presplitting blasting," Geofluids, vol. 20, 2021. 